\title{
¿NUEVAS SUJETAS, NUEVAS IDENTIDADES? LA VIVENCIA PROFESIONAL EN LA CONFI- GURACIÓN DE LA IDENTIDAD DE GÉNERO
}

New subjects, new identities? The professional experience in the configuration of gender identity

Liliana Ibeth Castañeda Rentería ${ }^{1}$

Fecha de recepción: 10 enero de 2017

Fecha de aceptación:23 abril de 2017 


\section{Resumen}

El texto da cuenta del proceso de constitución de subjetividades femeninas que ha permitido la vivencia profesional del trabajo asalariado. Analizo cómo el ingreso a la universidad, la elección de carrera y la experiencia de formación profesional, así como el ingreso al mercado de trabajo y la trayectoria laboral de mujeres profesionistas que trabajan, ubicadas en Guadalajara, Jalisco, México, posibilitaron la constitución de sujetos femeninos que se configuran a través y desde la profesión como mujeres con capacidades y posibilidades de individualización y desarrollo que las aleja de los referentes domésticos y maternales de la identidad femenina.

Palabras clave: sujeto femenino, trabajo, identidad de género.

\section{Abstract}

This text deals with the process of constitution of women's subjectivities enabled by the professional experience of wage labor. I discuss how entrance to college, career choice and the experience of formal training, as well entering the labor market and the career trajectory of professional working women, in Guadalajara, Jalisco, Mexico, have made possible the constitution of female individuals who shape themselves through and from the profession, as women with skills and possibilities of individualization and development, which separate them from the household and maternal reference points of female identity.

Keywords: female individual, work, gender identity. 


\section{Introducción}

$\mathrm{E}$ lobjetivo de este artículo es doble. Primero, sostengo que el ingreso a la universidad, la elección de carrera y la experiencia de formación profesional posibilitaron la emergencia de sujetos femeninos que se configuran a través de la profesión como mujeres con capacidades y posibilidades de individualización y desarrollo que las aleja de los referentes domésticos y maternales de la identidad femenina. Lo anterior nos coloca ante sujetos con una idea distinta sobre lo que implica vivirse como mujer que tiene su origen durante el proceso de socialización en la familia, pero que toma fuerza como parte medular del proceso subjetivo de estas mujeres en el trayecto universitario y el posterior ingreso al mercado laboral. Por lo tanto, arguyo que el trabajo profesional asalariado contribuye a la constitución de un sujeto mujer con referentes y proyectos de vida alejados de los modelos de esposas y madres, y que prioritariamente se viven en una dimensión pública de la vida social.

El segundo objetivo surge a partir de ahí. Con base en la descripción de la trayectoria académica universitaria y la de trabajo, problematizo la relación trabajo-poder-feminidad sobre la configuración identitaria de estas mujeres. La dimensión simbólica de poder y autoridad resulta un elemento indispensable en la configuración de subjetividades y en la adscripción identitaria femenina, pues posibilita lugares de enunciación con múltiples posibilidades de agencia.

Un primer elemento a considerar son los cambios estructurales que han permitido a las mujeres en nuestro país, y en general en América Latina, el ingreso a la educación superior. El proceso de inserción universitaria no tiene mucho tiempo, autores como Roberto Rodríguez consideran que el proceso de expansión y reestructuración en el nivel superior y universitario en la región latinoamericana estuvo comprendido entre la década de 1960 y la de 1980 (Rodríguez Gómez, 2000)

En nuestro país en particular, de acuerdo con Rodríguez Gómez, fue durante la década de los setenta cuando la matrícula se triplicó en parte por un efecto de expansión del sistema de enseñanza que implicó el impulso de la formación tecnológica orientada a las necesidades del proyecto desarrollista implantado en ese momento, pasando de 250 mil alumnos matriculados en este nivel educativo a casi 900 mil. A este proceso contribuyó de manera importante además de la diversificación institucional de la enseñanza superior y la regionalización de la matrícula, y la incorporación más numerosa de la mujer al espacio universitario (Brunner, 1985). ${ }^{2}$

La presencia de mujeres en los espacios universitarios posibilitó trayectorias biográficas donde la actividad laboral estaba contemplada. Además, contribuyeron a su inserción en espacios distintos al doméstico las políticas de control del crecimiento poblacional, a través de campañas dirigidas a mujeres en edad reproductiva que promovían la actividad laboral femenina como contribución al desarrollo nacional (Abrantes Pégo y Pelcastre Vilafuerte, 2008)

Con los años se ha demostrado que la incorporación de la mujer al mercado laboral es anticíclica, pues, aunque se incrementa en momento de crisis económica, no disminuye cuando éstas decresen ( $\mathrm{Pa}-$ checo, 2013). Como se puede observar, es necesario explorar los procesos subjetivos que tuvieron lugar y los que produciría la vivencia universitaria y por supuesto, la incorporación al mercado laboral.

2- Existe una amplia bibliografía que aborda la incorporación de las mujeres a la educación superior, para profundizar ver Roberto Miranda Guerrero (2007) y Araceli Mingo (2006). 
Las mujeres aquí abordadas, dan cuenta a través de sus relatos de resignificaciones en torno a las profesiones y sus prácticas. Así como también ponen sobre la mesa la necesidad de reconocimiento y prestigio social a través de ellas. Este será el objetivo de la primera sección de esta comunicación.

En la siguiente sección abordo la relación entre las categorías identitarias de profesión, género y trabajo en la experiencia de las informantes, con el objetivo de mostrar la complejidad de dicha intersección y analizar la manera en que dicha amalgama identitaria se conjuga en términos de 'poder' y feminidad. Algunas preguntas que guiarán la exposición y el análisis son ¿Qué papel juega el trabajo profesional en su subjetividad? ¿De qué manera el ejercicio de la práctica profesional implica o no resignificaciones en torno a la feminidad y sus atributos de entrega, sacrificio y servicio a los demás?

Teóricamente parto del concepto de identidad de género entendido como un proceso inacabado, encarnado, situado, histórico, que tiene su origen en la construcción y significación de la diferencia sexual y que organiza la experiencia de los sujetos en tanto hombres o mujeres en relación a otras categorías identitarias. De ahí la necesidad de analizar cómo esta categoría identitaria se ha visto trastocada por la educación profesional, el ingreso al trabajo en un momento histórico caracterizado por la disolución de referentes tradicionales, por ejemplo, el Estado, en la construcción de las identidades individuales y las posibilidades ilimitadas que ofrece el mercado (Bauman, 2010)

El material empírico que se analiza se produjo a través de las entrevistas biográficas a veintiún mujeres profesionistas que trabajan, con un rango de edad de entre 37 y 53 años y sin hijos. Para fines de este trabajo se analizan el caso de nueve de esas entrevistas que resultaron significativas para el tema abordado, y que no implica que las entrevistadas restantes no hayan presentado coincidencias con lo dicho por estas nueve mujeres. Se trata de relatos de vida, que fueron analizados con el apoyo del software Atlas ti en su versión 6.

Cierro el texto con algunas consideraciones finales. En esta parte presento el balance que hacen las informantes en torno a lo ganado, lo perdido, las renuncias, lo construido en relación a su práctica profesional y el vínculo de lo que socialmente se entiende como vida privada. Como expongo en el desarrollo del artículo, al día de hoy las mujeres profesionistas tienen claro que cada paso adelante en su desarrollo profesional implica renuncias y desapegos, saben que no se puede tener todo en la vida.

\section{E1 tránsito Universitario}

El incremento del ingreso de las mujeres a la educación superior, es un fenómeno relativamente reciente. Tanto, que no es hasta el año escolar 1999-2000, que la población estudiantil universitaria en nuestro país estuvo conformada por 50 por ciento mujeres y 50 por ciento varones según datos de la ANUIES. Pese a lo anterior, la distribución porcentual de la población total sigue colocando a las mujeres en situación de desventaja. Mientras que en 2010 el 17.2 por ciento de los hombres contaba con educación superior, en el caso de las mujeres ese porcentaje era sólo del 15.9, de acuerdo con datos del INEGI.

Ahora, si bien es importante plantear el incremento de la matrícula femenina en las instituciones de educación superior y su estudio en casos particulares por carreras o instituciones, resulta más relevante para los fines de este trabajo preguntarnos sobre la experiencia que las informantes tuvieron durante su formación universitaria y la implicación en su configuración identitaria y su subjetividad. ¿Qué las llevó 
a elegir la institución y la carrera que eligieron? ¿De qué manera la profesión elegida representaba sus aspiraciones como mujeres? ¿Qué papel juega el reconocimiento público de las capacidades profesionales en la configuración de estos sujetos mujeres? ¿Cómo juega la dimensión simbólica de poder y autoridad desde el ejercicio profesional en esta configuración?

Laura supo desde muy temprano que todo lo que tuviera que ver con números, fórmulas y operaciones no era lo suyo. Así que tenía la certeza de que se dedicaría a algo 'más social. Durante la preparatoria nació en ella una preocupación y al mismo tiempo una aspiración relacionada con algo llamado justicia. Se vio a sí misma impartiéndola, no le interesaba defender a los inocentes, o meter a la cárcel a los culpables. Lo tenía claro, ella quería ser una Juez.

La elección de la institución de educación superior donde estudiaría no fue difícil. Primero porque económicamente su familia no estaba en condiciones de pagar una universidad privada; y segundo, porque la universidad pública donde podía estudiar contaba con reconocimiento social en lo referente a la formación de los estudiantes como Abogados. Cuando egresó de la preparatoria hizo trámites a la Universidad de Guadalajara, a lo que en ese momento era la Facultad de Derecho.

"No quedé". No haber sido admitida en ese momento fue un duro golpe para Laura y para su familia, en particular para su padre quién había dejado trunca su educación universitaria precisamente en esa carrera. En ese momento existía la posibilidad de realizar un trámite en la institución que les permitía a los y las aspirantes no aceptados elegir otra carrera en la que hubiera vacantes. Las opciones de Laura eran Trabajo Social, Sociología, Geografía, entre otras. Ella quería volver a hacer trámites a Derecho, suponía que su examen había resultado mal y pensaba prepararse mejor para volver a intentarlo. Su padre le aconsejaba que realizara el trámite, pues le preocupaba que desistiera y finalmente no ingresara a la universidad.

Ese momento fue muy difícil porque mi papá me decía que no perdiera el tiempo, o sea que no perdiera esos seis meses, que me cambiara de aspiración a otra licenciatura, así que fui a formarme como muchos a hacer el cambio y en realidad llegué a la ventanilla todavía sin saber qué otra, porque yo quería ser Abogada, entonces, estaba Trabajo Social que era una opción más parecida a lo que yo quería ser, pero que en realidad no era lo que yo quería, yo quería realmente estudiar Derecho quería dedicarme a eso, no hice el trámite de cambio, llegué a la ventanilla y le dije siempre no y me salí.(Laura)

Laura ingresó un semestre después a la carrera que ella quería. La elección de la carrera no siempre resulta sencilla, ni depende en la mayoría de las veces de cuestiones relacionadas con la vocación. El seguir a las amigas, el no quedarse sin estudiar, la ambición económica y de prestigio social también tuvieron influencia en la decisión sobre qué carrera estudiar de estas mujeres. En los casos particulares de mis informantes, identifico dos elementos presentes en su elección profesional: la ambición económica, de prestigio y reconocimiento social, y la necesidad de distinguirse-diferenciarse de las mujeres de su familia y clase de origen. Ambos elementos tienen detrás la certeza de ser mujeres capaces de 'ser alguien' en la vida, lo cual estuvo íntimamente relacionado con la posibilidad que daba la preparación profesional universitaria para el ingreso al mundo del trabajo. También encuentro elementos significativos con rela- 
ción a las características de feminidad de algunas actividades profesionales, pero siempre mediados por el poder y no por características femeninas tales como el servicio o cuidado a los otros.

\subsection{Ambición económica, de prestigio y
reconocimiento social.}

Roberta siempre quiso ser médico, y no precisamente por un tema de cuidar a los demás o salvar vidas. En su familia materna había profesionales de la salud con mucho renombre, y eso era justo lo que a ella le atraía, "en primer lugar el prestigio que tenían, en segundo lugar que... tienen dinero (risas)".

Según relata, siempre estuvo inclinada a las ciencias naturales. Decidió estudiar la preparatoria en el CBTIS donde además obtendría el grado de técnico en análisis químicos clínicos, un paso ya planeado para su futuro profesional. También recuerda que su padre valoraba mucho el que sus hijos estudiaran y aprendieran de temas diversos, "en mi casa siempre hubo esta presión de no ser un idiota, un inculto" por lo que además de su interés por la biología o la medicina, a Roberta le importaba saber de historia, geografía y ciencias sociales.

Dos cosas fueron las que al final de sus estudios medios superiores llevaron a Roberta a cambiar su elección profesional. La primera que durante el quinto semestre asistió a una clase sobre historia prehispánica impartida por una maestra que logró despertar su interés por el tema. Pero, además, y ésta fue la segunda y más importante razón de su cambio de planes como futura médica, durante su servicio social en el hospital Valentín Gómez Farías en el laboratorio de análisis químicos y clínicos, observó de manera cercana la vida de los internos de medicina,

siempre estaban malhumorados, siempre estaban cansados, y trataban mal a cualquier persona que les rodeaba, trataban mal a sus pacientes, a los técnicos, a los laboratoristas, y yo los veía y decía, ¡ay no! iguácala!, yo no quiero ser médico, yo no quiero ser así[...] Yo dije, pues habrá otras formas de también obtener dinero.

Contrario a lo que Roberta pensó, su padre la apoyó cuando le dijo que quería estudiar antropología. Y no sólo eso, además le hizo ver que no necesitaba ser médico para ganarse el prestigio y el reconocimiento que deseaba al decirle: "tú vas a ser una mujer muy chingona". Admite que a sus padres sí les preocupaba el mercado laboral al que podría ingresar su hija, sin embargo, Roberta investigó y les hizo ver que si había trabajo, no para hacerse rica, pero si para vivir dignamente.

La preocupación de los padres de Roberta fue compartida también por otros padres de familia que pusieron sus expectativas de movilidad social de sus hijos en los estudios profesionales, sobre todo de carreras más institucionalizadas (Babb, 2003). El periodo comprendido entre 1940- 1970 conocido como "el milagro mexicano", permitió el ingreso a la universidad de varias generaciones de jóvenes mexicanos y por ende el egreso de varias de esas generaciones de profesionales que lograron obtener empleos bien remunerados en el área en que se habían formado profesionalmente, muchas veces sin siquiera estar titulados. Lo anterior fortaleció la idea de que la formación escolar era exclusivamente un asunto de preparación para el trabajo.

De acuerdo con Luna Santos (2005), el proceso de expansión educativa en el nivel superior dio inicio en los años setentas. Lo anterior fue posible gracias a que la política educativa nacional concibió la educación profesional como condición necesaria para el desarrollo. 
La mayor demanda de servicios educativos también tuvo que ver con factores sociodemográficos, dado que el volumen de población que en los setenta tenía la edad y la intención de ingresar a las instituciones de educación superior reflejaba, por un lado, la elevada fecundidad de los años cincuenta y sesenta y, por otro, una proporción importante de población que para la década de los setenta había terminado la educación media superior, particularmente en las ciudades (Luna Santos, 2005: 221)

El ingreso a la universidad posibilitada por las políticas educativas de la segunda mitad del siglo XX, representó para varias generaciones de mexicanos la posibilidad más real de ingresar al mercado de trabajo y de movilidad social, lo que Daniel Reséndiz llamaría la "coincidencia plena entre la política pública y la propensión social a tener un alto aprecio por la educación superior como factor de movilidad socioeconómica" (Reséndiz Núñez, 2000: 22). Casos como el de Roberta son significativos pues después de una infancia con serias limitaciones económicas, resulta lógico que la decisión sobre qué carrera estudiar esté mediada por la necesidad de lograr una situación de holgura económica.

Por otro lado, encontramos en este mismo caso la necesidad de reconocimiento social, que en un primer momento observa en la profesión médica, que no desaparece cuando elige la carrera de antropología y que Roberta obtiene en el momento que su padre le dice: "si hija, ¡adelante! Tu puedes ser lo que tú quieras en la vida, ¡tú vas a ser una mujer muy chingona!".

El caso de Camila también es un ejemplo de ese imaginario: “yo elegí administración, la verdad, no sé muy bien, la elegí, una, porque en el CUCEA iban a estudiar mis amigas, y pues también porque me parecía una carrera bien, pues si me imaginaba como trabajando como en una empresa como 'alta ejecutiva', cosa a la que no me dedico (risas)."

La existencia de un imaginario social alrededor de las diferentes profesiones y su naturaleza femenina o masculina no es un tema nuevo (Castañeda Rentería, 2013). Las ciencias sociales y las humanidades siguen siendo un nicho mayormente femenino, mientras las ciencias exactas y las ingenierías siguen teniendo un mayor número de alumnos varones. Prueba de lo anterior es que, de la matrícula del Centro Universitario de Ciencias Exactas e Ingenierías de la Universidad de Guadalajara, sólo el 24.7\% está integrado por mujeres, mientras que en el de Ciencias Económico Administrativas el porcentaje llega a 53.6 y en el Centro Universitario de Ciencias Sociales y Humanidades casi alcanza el 56\% ${ }^{3}$.

El anhelo de reconocimiento es también vivido por estas profesionistas como una forma de individualización dónde la preocupación por el bienestar de los demás no tiene que implicar el sacrificio del bienestar propio. Y es la educación superior la herramienta posible para estar bien, como lo ilustra el caso de Emiliana. Ella tiene muy presente un diálogo que escuchó en un camión entre dos mujeres. Una de ellas contaba que el haber sido la hija mayor, la había marginado en sus posibilidades de crecimiento personal, "nada les merecí", decía, pese a que apoyaba en las labores de cuidado de sus hermanos menores. Esa conversación impactó fuertemente a Emiliana, "yo soy la mayor en mi familia, entonces yo decía ¡no!, yo no quiero eso para mí, o sea, yo quiero que todos los demás estén bien, pero yo también quiero estar bien”.

3- http://www.escolar.udg.mx/estadisticas/alumnos/informe-de-matricula-inicio-de-curso-911-sep-2014-2015 Consultado el 15 de febrero de 2015. 
Emiliana construyó una trayectoria donde el eje era ella misma. Las condiciones familiares la llevaron a solicitar una beca de estudio durante su estadía en una universidad privada, pues la carrera de comunicación no se ofertaba en la universidad pública. De acuerdo con sus palabras, afirma con mucho orgullo ser la primera profesionista de su poblado. Emiliana es una mujer a la que le gustan los reflectores,

me encantaba por ejemplo, ya la parte de decir los discursos, de dar la bienvenida al Gobernador, cuando se daba el corte de listón de alguna obra pública en mi comunidad, este... me encantaba ser la que decía en los momentos cívicos escolares, me encanta así como el reflector. [...] entonces de ahí de mi orientación nació la comunicación, en la escuela, en la Institución en la que la estudié en la Autónoma, pues es una orientación, era una orientación más publicitaria y más paradójica, a mí me encantaba la parte periodística, las relaciones públicas y de más de ahí pues bueno le seguí anexando de ahí fue que... (Emiliana)

La abnegación y la entrega no son parte de lo que como mujer es Emiliana. Y aunque reconoce como una de sus características como mujer su capacidad de comunicación interpersonal, la elección de carrera obedeció a una resignificación de esa capacidad más allá de lo que es capaz como mujer. Esa capacidad se convirtió en un medio, una herramienta para lograr el reconocimiento y los reflectores que la hacen sentir plena.

En este sentido tenemos que las informantes si bien, pudieron elegir carreras 'femeninas' lo hicieron por razones distintas, es decir, no hacen alusión a 'ayudar a la gente,' 'educar', 'servir', sino a motivaciones relacionadas con una proyección de sí mismas como mujeres independientes, emprendedoras, con prestigio y poder.

\subsection{La distinción que da la universidad y el trabajo.}

Ximena es la mayor de diez hermanos. El único camino para salir de casa era el trabajo y la educación. Aunque admite que su padre siempre trabajó para darles lo necesario, pues en su casa nunca faltó comida ni educación para los que quisieron estudiar. Pese a que ni su madre ni su padre tenían estudios superiores, Ximena tenía muy claro que era a través de la educación y el trabajo que lograría mejorar su situación de vida, pero sobre todo apropiarse de su futuro, dejando de lado el modelo materno que justo le recordaba lo que ella no quería ser ni hacer.

La educación, aunque siempre fue algo deseable para los padres de Ximena, no tenía que ver únicamente con un asunto de obtener un buen trabajo, sino también de ser un camino posible para ella como mujer y ver la escuela como un elemento clave para diferenciarse como tal de los referentes femeninos más cercanos. Ximena relata que sus aspiraciones profesionales no fueron fundadas en ambición económica. Recuerda que le encantaba saber, y siempre quería saber más, estar en contacto con personas interesantes y sobre todo quería dedicarse a algo que no le implicara una rutina de actividades diarias.

En un artículo publicado en 2007, Miranda Guerrero observa que el tránsito universitario es visto por las mujeres estudiantes como "un medio para el tránsito hacia el trabajo remunerado y hacia una vida no 
limitada a la esfera doméstica" (Miranda Guerrero, 2007: 19). Lo cual coincide con otros trabajos donde se plantea la existencia de una brecha importante entre las propias mujeres en cuanto a su participación económica en relación a su nivel de instrucción, Edith Pacheco señala, "Así, una tasa de participación económica de $25 \%$ de las mujeres sin instrucción se observa frente a una tasa del $60 \%$ de mujeres con estudios universitarios" (Pacheco, 2013: 59)

Miranda también identifica cómo para algunas estudiantes universitarias de primera generación el ingreso a los estudios superiores es además una 'conquista' que les permite no sólo vislumbrar un futuro laboral, sino también les da acceso a ejercer 'influencia', como forma de poder, al interior de sus familias y círculos cercanos. (Miranda Guerrero, 2007)

Las mujeres que participaron en este trabajo son prueba de ello, pues reconocen mediante sus relatos, cómo el graduarse de una carrera universitaria o ya desde su tránsito por la universidad, su voz "peso" en las decisiones familiares, situación que se acentúa en los casos dónde además de estudiar trabajaban y aportaban dinero a la familia.

\subsection{Los estudios universitarios y la familia.}

A diferencia de sus madres, las mujeres que participaron en esta investigación como informantes, no concebían la posibilidad de quedarse sin estudiar. Para ellas era un paso lógico, lo que seguía. Si acaso en algunos momentos eran las condiciones económicas de la familia lo que les significaba algún tipo de obstáculo.

Además, varios de los padres de familia ya contaban con educación superior y empujaron a sus hijas a prepararse. Otros, tanto padres como madres, vieron en sus hijas e hijos la posibilidad de realizar lo que ellos habían ansiado hacer, pero que en su momento las condiciones familiares, sociales, culturales y económicas particulares no les habían permitido.

En la mayoría de los relatos se da cuenta de cómo los padres y madres de estas mujeres consideraron la importancia de la educación en la vida de sus hijas. La idea de la educación como la mejor herencia que un padre puede dejar a sus hijos estuvo presente en el caso de las informantes. Si en algún momento existió la posibilidad de no estudiar, fue por condiciones de índole económica, que en varios casos se subsanó gracias a gestiones logradas para la obtención de becas o el ingreso al mundo del trabajo previó al egreso de la universidad.

\section{Cuadro 1. Nivel Educativo de Padres y Madres de las informantes}

\begin{tabular}{|c|c|c|c|c|c|}
\hline & Informante & Edad & $\begin{array}{c}\text { Nivel educativo } \\
\text { alcanzado }\end{array}$ & Nivel educativo Madre & $\begin{array}{c}\text { Nivel Educativo } \\
\text { Padre }\end{array}$ \\
\hline 1 & Cecilia & 40 & Licenciatura & Preparatoria & Preparatoria \\
\hline 2 & Berenice & 40 & Candidata a Doctora & Cuarto de Primaria & No sabe \\
\hline 3 & Ximena & 41 & Maestría & Primaria Trunca & Secundaria \\
\hline
\end{tabular}




\begin{tabular}{|c|c|c|c|c|c|}
\hline & Informante & Edad & $\begin{array}{l}\text { Nivel educativo } \\
\text { alcanzado }\end{array}$ & Nivel educativo Madre & $\begin{array}{c}\text { Nivel Educativo } \\
\text { Padre }\end{array}$ \\
\hline 4 & Carmen & 53 & Candidata a Doctora & Comercio & Abogado \\
\hline 5 & Siphora & 53 & Maestría (2) & Tercero de primaria & Técnico tornero \\
\hline 6 & Elizabeth & 38 & Maestría trunca & Primaria & Secretariado \\
\hline 7 & Laura & 39 & Candidata a Doctora & Tercero de primaria & $\begin{array}{l}\text { Carrera universita- } \\
\text { ria trunca }\end{array}$ \\
\hline 8 & Gema & 47 & Maestría & Comercio & Cuarto de Primaria \\
\hline 9 & Roberta & 37 & Maestría & Comercio & $\begin{array}{l}\text { Administración y } \\
\text { Letras y Periodismo }\end{array}$ \\
\hline 10 & Analía & 40 & Licenciatura & Secundaria & Artes Plásticas \\
\hline 11 & Silvia & 41 & Licenciatura & Comercio & Ingeniero Geólogo \\
\hline 12 & Sofía & 44 & Doctorado & Tercero de Primaria & $\begin{array}{c}\text { Segundo de secun- } \\
\text { daria }\end{array}$ \\
\hline 13 & Camila & 38 & Candidata a Doctora & Odontóloga & No sabe \\
\hline 14 & Luna & 42 & Candidata a Doctora & Primaria & Primaria \\
\hline 15 & Emiliana & 44 & Maestría (2) & Segundo de primaria & Abogado \\
\hline 16 & Cinthia & 38 & Doctora & Primaria & Primaria \\
\hline 17 & Guadalupe & 39 & Maestría (2) & Secundaria & No sabe \\
\hline 18 & Patricia & 47 & Maestría (2) & Secretariado & Comercio \\
\hline 19 & Fernanda & 41 & Maestría & Docente normalista & $\begin{array}{l}\text { Piloto Aviador } \\
\text { Carrera Militar }\end{array}$ \\
\hline 20 & Gabriela & 44 & Licenciatura & Primaria & Primaria \\
\hline 21 & Karla & 44 & Maestría & Primaria & Preparatoria \\
\hline
\end{tabular}

Fuente: Elaboración propia

De las veintiuna mujeres entrevistadas, nueve trabajaron al mismo tiempo que realizaban sus estudios universitarios. La mayoría por necesidad económica. Sin embargo, algunos casos como los de Berenice, el ingreso al mercado laboral previo al egreso del pregrado le permitió demostrar (se) su capacidad y su valor como mujer y profesionista. Las legitimó y les permitió ejercer cierta autoridad como adultas y profesionistas mujeres.

Berenice ingresó a la carrera de psicología en la Universidad de Guadalajara. Un semestre después decidió que eso no era lo suyo. Investigó y supo de la carrera de comunicación. La opción que era viable para ella era una institución privada. Sin embargo, pese a que gestionó y obtuvo una beca del 25 por ciento en la colegiatura, sentía carga moral con su tía, su mamá y su hermano, quienes mes con mes le daban dinero para que siguiera sus estudios. 
Ya durante su trayecto universitario y motivada por su vocación, recibió el mejor consejo que un profesor pudo darle, buscar espacios para la práctica profesional en los medios de comunicación. Sintiéndose "sobrada" dice ella, decidió hacer solicitud en el periódico El Financiero, que quedaba cerca de su casa. Para su sorpresa le hablaron al día siguiente, no sólo le permitirían hacer actividades relacionadas con su profesión, sino que además le pagarían. Toda esta experiencia configuró a Berenice como una mujer capaz y segura,

me sentía muy bien, a esa edad me dieron la oportunidad de abrir un evento, que se hizo en la UdeG cuando ya estaba como 4 meses en redacción, y no pasaba que rápido te llevaran a reportear, tenías que pasar un periodo de entrenamiento y ver ya mi nota y mi nombre publicado fue muy (suspiro)... bueno, guardarlo, hacer mi portafolio y publicar en la página principal siendo yo estudiante, para mí eso fue muy estimulante y me permitió mostrarle a mí familia que había decidido bien y estaba haciendo lo que me gustaba y yo creo que eso los conmovió mucho... ahí estaba yo, con el mejor promedio de mi generación y trabajando, por la que nadie daba un peso (Berenice)

Como lo menciona Tolentino, "los campos de la escolaridad y de la profesionalidad adquieren un rango de legitimidad importante en la construcción de categorías sociales; el empleo, el trabajo y la formación se constituyen en dominios pertinentes para los individuos en su proceso de identificación social" (Tolentino Arellano, 2013: 201).

Una característica común de las informantes es su gran interés por seguir preparándose. Tal como lo muestra el cuadro 2 sólo cinco de las entrevistadas no cuentan con estudios de posgrado. Y siete de ellas cuentan con estudios doctorales. Por lo demás, la totalidad de mujeres ha tomado cursos de actualización disciplinar, diplomados, idiomas, así como cursos de automaquillaje, costura y repostería.

Cuadro 2. Nivel Educativo alcanzado por las informantes

\begin{tabular}{|c|c|c|c|c|}
\hline \multirow{2}{*}{ Informantes } & Estudios de Pregrado & Maestría & Doctorado & $\begin{array}{c}\text { Informantes con cursos } \\
\text { de actualización e } \\
\text { idiomas }\end{array}$ \\
\hline 21 & 21 & 16 & 7 & 21 \\
\hline
\end{tabular}

Fuente: Elaboración propia

Lo anterior coincide con otros estudios en los que frecuentemente las mujeres están 'sobre-calificadas', generalmente obtienen diplomas y credenciales por su cuenta e interés propio (no por parte del empleador) haciéndose ellas mismas responsables de su competencia (Tolentino Arellano, 2013)

La presencia de las mujeres en las aulas universitarias también es evidente en el posgrado. Según consta en la página de Control Escolar de la Universidad de Guadalajara, el 53\% de su matrícula de posgrado está constituida por varones mientras el $47 \%$ son mujeres. 
Como se puede observar el acceso a las aulas universitarias es esencial en el análisis de la configuración identitaria de las mujeres que participaron en este trabajo. La formación profesional fue el medio a su alcance para diferenciarse y lograr objetivos de reconocimiento, independencia y autoridad en el círculo familiar. La identidad profesional ha sido estudiada como un proceso de socialización al interior del mundo del trabajo (Romo, 2000), sin embargo, los relatos obtenidos dan cuenta de la importancia que en la configuración de la identidad profesional tiene el imaginario no sólo del campo laboral específico de la profesión sino también del profesional, en el caso que me ocupa, del prestigio y posición económica que proyecta.

El ingreso a la universidad no sólo ofrece un conjunto de conocimientos para ejercer la profesión, sino que también -y no como parte del currículo- la vida universitaria te forma en el "saber ser", y se constituye como un proceso que 'enviste' al sujeto y legitima su actividad mediante el otorgamiento de credenciales (Castañeda Rentería, 2007)

Ahora bien, reconozco la importancia de la institución universitaria y el proceso de formación profesional como parte esencial en la configuración identitaria de mujeres como Laura, Emiliana, Berenice, Ximena y Camila, considero que esa vivencia les permitió pensarse y vivirse como mujeres autónomas, autosuficientes y capaces.

Existen trabajos como el de Marrero y Mallada en Uruguay que presentan el espacio universitario como un espacio contradictorio en donde se siguen viviendo, padeciendo prácticas sexistas pero que al mismo tiempo logran constituirse como espacios determinantes para que las mujeres se constituyen como sujetos en la definición de sus proyectos de vida, gracias dicen, a la existencia de un discurso 'ideológico' universalista y supuestamente vertebrado por valores de equidad e igualdad. (Marrero y Mallada, 2009)

Sin embargo, también es importante destacar el apoyo y la concepción que sus padres y madres tenían sobre la educación en general y sobre la universitaria en particular. Como lo señala María Eugenia de la O en el caso de mujeres ejecutivas, "la identidad profesional femenina de las ejecutivas se configura tanto en la empresa como en otros ámbitos de socialización como la escuela, las relaciones sociales, la familia de origen y la propia" (De la O, 2013: 20)

En la siguiente sección abordaré la relación entre las categorías identitarias de profesión, género y trabajo en la experiencia de las informantes, con el objetivo de analizar la complejidad de dicha intersección, como y la manera en que dicha amalgama identitaria se conjuga en términos de 'poder' y feminidad.

\section{Profesión, género y trabajo: la configuración de una feminidad con poder}

En esta sección sostengo la idea de que es el trabajo profesional el núcleo que configura la identidad de las mujeres sujetos de esta investigación, pues es su actividad laboral la que organiza su vida y enmarca su experiencia como mujeres. Como se expuso en la sección anterior, varias de las entrevistadas ingresaron al mercado laboral aún antes de su egreso de la universidad. Lo anterior sin duda contribuye, al igual que el ingreso al trabajo en otros momentos, a una resignificación de lo público y lo privado-doméstico como espacios posibles en estas trayectorias biográficas femeninas. Además de lo anterior, encuentro que el quehacer profesional y las posibilidades económicas, de autoridad y decisión que construye esta combinación, configuran sujetos que también construyen sentidos distintos sobre los atributos femeninos 
desde otros lugares de enunciación. Hablo de feminidades con atributos distintos a la entrega, el servicio y cuidado de los demás, mujeres con poder para ayudar a los demás, sin sacrificarse a sí mismas, por un lado, por el otro, se trata de mujeres que configuran su identidad femenina desde el poder que ejercen en $\mathrm{y}$ desde su ejercicio profesional.

De acuerdo con Edith Pacheco (2013) los estudios que abordan la participación económica femenina son expresión tanto del interés de quienes abordan los estudios sobre mujeres, como también de los estudiosos del tema de lo laboral. Esta misma autora señala la evolución de estos tipos de trabajos, identificando por ejemplo que para la década de los setentas y ochentas la 'consigna' era "sacar de la invisibilidad a la mujer" (Pacheco, 2013: 36). Para los noventas, se introduce la perspectiva de género y los estudios sobre participación económica femenina complejizan su abordaje a partir de las articulaciones entre clase, género y etnia.

La incorporación de las mujeres al mercado de trabajo se ha hecho en circunstancias de crisis económicas, pero de acuerdo con De la O (2013) diversos indicadores han mostrado que la inserción femenina a las actividades económicas ya es anticíclica. Pese al innegable aumento de mujeres en la esfera laboral, la tasa de participación laboral femenina en México es la más baja en América Latina (Damián, 2013)

Las trayectorias laborales de las mujeres entrevistadas tienen en común la rápida inserción al mercado de trabajo una vez egresadas de la universidad -varias de ellas incluso antes-, y una búsqueda constante por nuevos retos y proyectos profesionales que las ha llevado en algunos casos a tener trayectorias laborales en varias instituciones, en distintas áreas dentro de alguna organización o a emprender proyectos empresariales por su cuenta.

El trabajo profesional constituye el núcleo organizador de sus vidas, no sólo en relación a sus ingresos y las posibilidades de acción que esos ingresos permiten, es decir lo que el trabajo les permite 'tener', sino también por lo que el trabajo les permite 'ser'. Aquí me refiero en particular a la autodefinición como mujeres 'que pueden', mujeres con autoridad, que ejercen poder, sea para ayudar a los demás, sea para darse a respetar y ganar prestigio y reconocimiento social.

\subsection{Ejercicio profesional femenino: “cuando se tiene poder para ayudar a los demás"}

Karla es de un pueblo llamado Juanacatlán. Tiene 44 años. Su madre prácticamente la obligó a venirse desde los 15 años a vivir sola a Guadalajara para que continuara sus estudios. Su padre murió cuando ella tenía sólo once años y su madre nunca se volvió a casar. Su familia es sumamente religiosa por lo que más de alguna vez pensó en dedicarse a la vida religiosa.

Finalmente decidió estudiar Trabajo Social. Le parecía que era una carrera en dónde podía vivir y poner en práctica principios y valores que para ella eran importantes. Aunque no lo dice expresamente, para ella la ayuda al prójimo, la defensa del indefenso, la prevención de la violencia, son principios que han sido determinantes para decisiones laborales. Como, por ejemplo, su participación en programas preventivos de la violencia contra mujeres y niños en la Secretaría de Salud del estado, o las gestiones que ha realizado por más de diez años para hacer posible la construcción y puesta en funcionamiento de un hospital en su pueblo. 
Pese a que se pudiera decir que este tipo de actividades se encuentran en el marco de lo propiamente femenino, considero que el caso de Karla da muestra de un cambio del sentido sobre la preocupación, protección y cuidado del otro, donde el 'olvido de sî́ no aparece como condición necesaria.

Karla recuerda que en la escuela siempre fue una alumna contestataria. A eso atribuye que durante su formación universitaria y luego en su ingreso al mundo laboral, se haya convertido en una activista y 'excelente' gestora. Reconoce que se siente orgullosa de tener alumnos y alumnas que quieran seguir sus pasos. También hay muestras de orgullo y satisfacción cuando habla de sus trabajos, del hospital, de hasta donde es capaz de ayudar a los otros.

Como se puede observar, el caso de Karla es interesante porque resignifica desde la esfera pública y profesional prácticas a través de las cuales es posible dar cuenta de un sujeto femenino con una relación distinta con el otro al que se da, al que cuida, al que protege. Karla es una mujer que para dar, ayudar y cuidar no se olvida de sí, por el contrario, se vive como una líder, contestataria, activista, y es eso lo que le permite darse bajo sus propios términos: "me gusta ser Jefa, me gusta liderear" (Karla)

El caso de Gema también resulta ilustrador para el análisis sobre la identidad femenina y su resignificación a partir del ejercicio de la profesión y el ámbito público donde se lleva a cabo. La elección de la carrera de psicología de Gema estuvo inspirada por un grupo de 'drogadictos' que conoció cuando tenía alrededor de doce años. Ahora, a sus 47 años reconoce que jamás ha dedicado su trabajo profesional al tema de las adicciones, pues egresando de la universidad tuvo 'la suerte' de 'comprar' una plaza en el área de educación especial en una escuela de nivel preescolar que es a lo que actualmente se dedica. Cuando se le preguntó por qué le gustaba su trabajo, Gema respondió:

me gusta me gusta mi área, este me encanta el contacto con la gente, así como cuando me dices recuerdo esa parte de... no me dedique con los drogadictos pero hay mamás que se me acercan y me cuentan o así como escúchame y eso es lo que me hace sentir satisfecha y es cuando yo digo, bueno el trabajo con los niños este hasta con los chiquititos de preescolar, que uno ve respuestas y yo digo es que ese es mi trabajo es lo que a mí me gusta, y él [un compañero psicólogo] me dice es que hay yo estar con los alumnos no, ellos son docentes, es otro boleto, y yo nada más lo escucho, pero este yo me siento satisfecha con la carrera que elegí...

También trabajó durante 21 años como profesora de preescolar en una institución en la que se atendían niños de familias de escasos recursos. En ese trabajo no recibía salario, pero se sentía muy satisfecha de poder ayudar, no sólo impartiendo clases a los chiquitos, sino ejerciendo de Directora de la institución. Cuando se llevó a cabo la entrevista, hacía un año que Gema había dejado de trabajar en esta escuela.

Una situación muy parecida vive en la escuela donde tiene su plaza. Gema relata que apenas llegó a la institución la Directora, que en ese momento tenía aproximadamente 80 años, la convirtió en su mano derecha, "Es que soy más que escolar" asegura, refiriéndose a que no sólo es capaz de ejercer la docencia.

Con los años y debido al ejercicio de una autoridad que no le correspondía, se ganó un lugar y alguno que otro apodo por parte de sus compañeros y compañeras, debido a su nivel de exigencia en el desempeño del trabajo. Con los años y pese al cambio de administración, Gema sigue ejerciendo autoridad y realizando trabajos que no le corresponden y que la mantienen en una lucha interna constante, "a veces 
no quiero ni pensar, y hay gente que me dice: 'tú tampoco no dejas el puesto, ahí sigues', y yo la verdad, ¿para qué te miento? Haciendo bilis [...] pero me gusta, si está el trabajo siento esa satisfacción porque yo lo hice". Parte del porqué sigue haciendo trabajo que no le corresponde, asegura Gema, lo hace porque el director es incumplido y mal hecho, "es un hombre (risas) es difícil trabajar con hombres".

En un espacio feminizado cómo la educación preescolar, Gema tiene un concepto muy particular del trabajo que realiza su jefe varón. ¿Le hace el trabajo?, sí, pero se asegura de que la coordinadora de zona se entere y más de alguna vez, la propia coordinadora le ha reconocido públicamente su buen desempeño.

En este caso es notorio como la necesidad de la afirmación al trabajo realizado, está atravesado por las posibilidades que ese reconocimiento otorga no sólo para ayudar a los profesores, psicólogos y los niños y niñas de esa institución educativa, sino también por el ejercicio de poder que conlleva en sí mismo. Gema hace un trabajo que no le corresponde, pero 'necesita' hacer para conservar su posición política en la escuela y fuera de ella, pues en su familia la autoridad ejercida en su lugar de trabajo la posiciona de manera distinta frente a sus hermanos, hermanas y sobrinos.

Ella sabe que esto tiene un costo, algunos compañeros y compañera le han hecho saber que la consideran una 'chucha', que es muy 'perra' para su trabajo y con los que no hacen lo que les corresponde, ha tenido problemas con el sindicato y con varios colegas. Sin embargo, no le importa, al contrario, dice sentirse orgullosa porque esos adjetivos o sobrenombres, son producto de que sabe hacer su trabajo, lo hace bien' y de que es muy trabajadora. Gema se considera una mujer muy honesta, responsable, organizada, legal, cumplidora, administrada, franca, comprometida y eso es lo que según ella le ha permitido llegar a la posición que tiene en la escuela.

Como se puede ver con los casos de Karla y Gema, atributos femeninos relacionados con el servicio, cuidado, protección a los demás, así como adjetivos comúnmente asignados al trabajo femenino como administrar y organizar, han constituido para estas mujeres herramientas u objetivos que fortalecen su individualidad, pero que además las empodera gracias al reconocimiento que de su trabajo se hace en la esfera pública.

Nos encontramos así con sujetos femeninos, constituidos desde el espacio público, desde el espacio que permite la individualización, donde nos dice Amorós "no todos tienen el poder, pero al menos pueden tenerlo, son percibidos como posibles candidatos o sujetos de poder" (Amorós, 1994: 26). Estamos ante mujeres que para 'darse a los demás' se constituyen en sujetos femeninos con poder, lo que les posibilita darse en la medida que ellas desean, en los tiempos que ellas eligen y sin sacrificar su vida privada.

\subsection{Ejercicio de poder como profesionista mujer: "yo me en cargué de darme a conocer como una perfecta hija de la chingada"}

A diferencia de Gema y Karla, encontramos los casos de Roberta y Cecilia. Si bien a grandes rasgos podría decir que se trata también de mujeres con autoridad, liderazgo y mando, difieren de los casos anteriores pues no se resignifican atributos 'femeninos', sino que es la propia feminidad lo que es construida a partir de relaciones de poder donde ellas se ubican en posiciones privilegiadas.

En este trabajo concibo feminidad como la expresión de la identidad de género en el marco de lo que sociohistóricamente se ha construido como lo femenino. Dicha expresión se da a través de prácticas y 
sentidos vividos como lo propio de las mujeres en un momento y lugar específico. Lo que aquí analizo es justo la manera en que estas prácticas y sentidos se ven interpeladas cuando las mujeres experimentan, por ejemplo, el espacio público como propio.

Roberta es antropóloga. Como se mencionó en un apartado anterior, ella quería convertirse en médico para ganar dinero y prestigio. Luego se dio cuenta que el precio que esa profesión cobraba para tal efecto era demasiado alto y prefirió cambiar su elección profesional. Según relata tuvo su primera experiencia laboral apenas egresando de la carrera. Fue contratada para colaborar en un proyecto arqueológico en el Estado de Tamaulipas en donde trabajó cinco años por contrato de prestación de servicios temporales. Después de esa experiencia regresó a Guadalajara y ganó una plaza en una institución dedicada a la investigación, en donde actualmente sigue laborando.

El padre de Roberta tenía dos carreras universitarias y tuvo una niñez económicamente holgada. Su madre estudió con profesores privados hasta la secundaria, y aunque su padre no le permitió seguir estudiando la preparatoria, contaba con un capital cultural importante. Después de casarse la pareja vivió momentos de crisis económicas atroces. Sin embargo, recuerda Roberta "en la casa siempre hubo la presión de no ser un idiota, un inculto", y con golpes de por medio, tanto ella como su hermano aprendieron que el saber y demostrar lo que sabían, era un medio que facilitaba la supervivencia.

Como estudiante Roberta dice haber sido brillante, aunque recuerda que siempre tuvo problemas de disciplina:

Muy buena estudiante. Buenos promedios siempre, pero siempre con muchos problemas de disciplina, este, nunca me ha gustado que me den órdenes, yo creo que por eso muy pronto en mi desempeño como antropóloga fui subiendo en la estima de los que fueron mis jefes porque yo aun siendo subcontratada me gustaba que me considerarán como alguien con carácter y de valor, para estar por encima de mis demás compañeros contratados, y que me delegaran, siempre me ha gustado que me deleguen responsabilidades porque me gusta ejercer la autoridad, me gusta el poder. [...] Mi experiencia personal es que yo nunca he tenido problemas con hacerme oír porque yo tengo un carácter fuerte, si, entonces me he dado a la tarea de mostrarme siempre frente a mis trabajadores como una perfecta hija de la chingada, y básicamente eso es lo que ocurre con las mujeres, arqueólogas, antropólogas, a donde quieras que vayan a una comunidad no puedes tener una actitud liviana, ni de una princesita porque te comen (Roberta).

Como se puede observar en el testimonio, el valor que como profesionista tiene Roberta está íntimamente relacionado con el nivel de autoridad y mando que pueda desplegar sobre los otros. Pero lejos de considerar este adjetivo de 'hija de la chingada' -en relación a su poder respecto a otros-, como una manera de replicar roles o atributos masculinos, Roberta se ufana de ello y lo considera como atributo individual que no sólo la distingue de las demás mujeres sino además le otorga más valor: "todos mis trabajadores me han mostrado respeto, sería muy espantoso decirte que se me cuadran pero, eh, nunca nadie me ha faltado al respeto ni han desatendido mis indicaciones".

Lo que encuentro en casos como el de Roberta, es la configuración de una feminidad con atributos hasta cierto punto masculinos (mando, poder, carácter fuerte, ambición) que desde la experiencia subjetiva de estas mujeres son aprehendidos y vividos, construyendo para sí una 'feminidad desde el poder'. 
La feminidad desde el poder rompe con la idea de una feminidad con atributos de entrega, sacrificio y servicio. Se trata de una feminidad construida desde una posición legítima de autoridad, lograda a través del trabajo profesional, donde el despliegue de dicha autoridad, la exhibición del ejercicio del poder sobre los otros, constituye y distingue al sujeto femenino del resto de mujeres. Que además te coloca en una posición más horizontal respecto a los varones.

Otro caso que es útil para analizar la construcción de la feminidad desde y con poder es el de Cecilia. Indisciplinada en la escuela, criada por su madre que se divorció de su padre cuando ella tenía apenas siete años. Cecilia también contaba con un capital cultural y social importante, dada la posición social y económica tanto de su familia materna como la paterna. Estudió en una universidad privada la carrera de Arquitectura, con especialidad en urbanismo.

Al momento de la entrevista, Cecilia tenía una relación laboral con una empresa productora llamada Container One, donde es Productora Ejecutiva de fotografía fija en el área internacional. De acuerdo con lo que relata en la entrevista, apenas salió de la universidad se convirtió en productora, y atribuye esto a que cuenta con la personalidad para 'mandar',

Curiosamente desde que me titulé, me hice productora, no sabía que ese era el título hasta ahora que tengo siete años siendo productora, pero se me da muy grueso, digo, en Expo Arte, pues yo tenía 150 gentes bajo mi cargo y eso es lo que a mí se me da, dar órdenes y decir que a cada quién y asegurarme que cada quién está haciendo bien lo que tiene que hacer. Y ya, jamás volví a ejercer, la verdad es que trabajé mientras estuve en la escuela, me titulé como urbanista, hice varios, este, estudios urbanos pero, pero mientras estuve estudiando después me dediqué a la producción...producía eventos así como Expo Arte Guadalajara. (Cecilia)

Me parece entonces que lo que pudiera ser leído como un acercamiento a estereotipos de un modelo masculino, tal y como Sanhueza Morales lo propone en su trabajo sobre mujeres trabajadoras de clase media en Chile (Sanhueza Morales, 2005), se trata de la construcción de una feminidad con atributos distintos a los tradicionalmente asignados, pero no por ello menos femenina.

Lo que tenemos son voces de sujetos que se asumen como mujeres, pero no sólo como mujeres, sino como 'mujeres profesionistas' que trabajan, constituidas como sujetos desde la esfera pública, pero no sólo desde ella. Trabajos como el de Tolentino dan cuenta de la importancia que para la configuración de la identidad de mujeres que trabajan tiene la profesión, pero también la familia y la vida privada como un espacio propio (Tolentino Arellano, 2013)

Las mujeres profesionistas trabajadoras que participaron en mi investigación, provienen de familias donde la educación en general y universitaria en particular fue un signo de prestigio, movilidad social y autoridad al interior de las familias, lo que les permitió constituirse como sujetos desde la intersección de lo público y lo privado, primero desde los espacios universitarios y luego desde la posición laboral donde ejercen su profesión.

Me parece además, que son sujetos que desde su práctica resignifican la feminidad en relación a otras mujeres. Es el trabajo el organizador de su vida y el espacio desde donde se enuncia el sujeto femenino y se vive la experiencia de ser una mujer profesionista trabajadora sin hijos. Mujeres que viven su femini- 
dad resignificando 'el ser para los otros', que configuran su identidad apropiándose de atributos que las distinguen de las otras mujeres.

La construcción de una feminidad desde poder implica reconocer a estas mujeres como sujetos que en un contexto que ofrece múltiples opciones del tener y del ser, el momento posmoderno, eligen el poder como articulador de lo que las define como mujeres, como profesionistas y como trabajadoras.

El trabajo se vuelve así la posibilidad de ser basado en el reconocimiento desde el espacio público. La trayectoria laboral de estas mujeres ha implicado tomar decisiones importantes con relación a sus familias de origen, parejas y amigos. Desde vivir solas, sufrir las tensiones que implica seguir viviendo con los padres y sujetarse o no a las normas paternas, los acuerdos de pareja con relación a los quehaceres domésticos, dobles jornadas, los gastos domésticos, las tensiones originadas por ingresos dispares (sobre todo si la mujer gana más) o por ejemplo no encontrar pareja.

Sin embargo, ninguna de las mujeres entrevistadas considera alto el costo de su vida profesional y rescatan 'lo positivo' de los estilos de vida que han logrado gracias a su desempeño profesional. Son además mujeres que se vuelven agentes activos en el diseño y trayectoria laboral, piden aumentos salariales, promociones, oportunidades de desempeñar trabajos que representen retos intelectuales y laborales, lo cual no coincide con lo que autoras como Gina Zabludowsky explica como un elemento cultural del por qué las mujeres no llegan a puestos ejecutivos importantes en nuestro país, haciendo referencia al cómo las mujeres 'esperan' el reconocimiento de los jefes para alguna promoción, 'esperan' el momento oportuno para hablar con ellos, etc. (Zabluodvsky Kuper, 2014)

El caso de Carmen es claro,

Pues empecé trabajando en el banco a los... ¿qué año sería, qué edad tenía?... tenía dieciocho años... diecinueve años tenía, y transcurrieron quince años ahí, ahí tuve una carrera se puede decir también, porque ingresé como cajera y fui también ascendiendo en cargos, generalmente este no fue porque me propusieran sino porque yo pedía "oigan quiero, aquí hay una vacante por favor considérenme" hay un escalafón y un proceso, también un procedimiento ... incluso ocupaba puestos en los que generalmente estaban hombre, como el que le llamaban de la Cámara de Compensación que es donde se cambiaban los cheques de todos los bancos, generalmente iban más los hombres en la tarde, después de que tú estabas en sucursal, en la tarde ibas a hacer esa, había un departamento especial para eso, para eso, y este me decían, "no, no, tú no puedes estar en ese cargo y son puros hombres" y realmente eran puros hombres yo era la única mujer que iba, si acaso iban mujeres eran mujeres que suplían a quién estaba porque se iba de vacaciones, pero yo si quería ese cargo y tuve ese cargo y después de eso como que tuve un proceso mucho más rápido no en uno u otro puesto, hasta que llegue a una Gerencia, luego a proyectos de Mercadotecnia, en donde armaban equipos para, para este capacitación en las sucursales, sobre todo en el aspecto de ventas, y este y ahí me quedé en ese nivel. (Carmen) 
Sin duda, los trabajos realizados con relación a la incorporación de las mujeres al mundo del trabajo y la evolución de su participación en el mercado laboral hasta nuestros días ${ }^{4}$ dan cuenta de transformaciones en las relaciones entre hombres y mujeres visibles por ejemplo en los distintos acuerdos y organización familiar (Ariza y De Oliveira, 2006). Estos trabajos tienen como base la idea de que no puede medirse la participación de las mujeres en el mercado laboral sin compararla con la participación de los varones.

Si bien lo anterior es atinado, hace falta dar cuenta de cómo la participación de las mujeres en el ámbito público desde el trabajo asalariado de tiempo completo, está transformando no sólo las identidades de sujetos en lo particular, sino también el cómo desde su lugar de enunciación dan cuenta de la resignificación de lo que significa ser una mujer que trabaja. El trabajo se ha tornado para muchas mujeres en una "exigencia individual e identitaria, una condición para realizarse en la existencia, un medio de autoafirmación” (Lipovetsky, 2012 [1999]: 204)

\section{Consideraciones finales de la relación trabajo-poder-feminidad}

Sin duda uno de los cambios más importantes en las últimas cuatro décadas ha sido el aumento de la participación femenina en la educación superior. De acuerdo con datos publicados por Gina Zabludowsky en 2014, dicha participación pasó de un 17\% en 1970 a un 50\% en 2011. Además, han superado en eficiencia terminal a los varones con un porcentaje de 55\% del total de estudiantes titulados en las instituciones de educación superior (Zabludowsky Kuper, 2014)

La vivencia del espacio universitario ha marcado la vida de muchas generaciones de mujeres. Para algunas, como es el caso de las que participan en esta investigación, fue el momento a partir del cual se convirtieron en agentes de su propia constitución como sujetos sociales y ganaron en legitimidad y autoridad frente a otros.

Otro aspecto a tomar en cuenta es que las mujeres que aquí hablan, se formaron profesionalmente coincidiendo en la década de los ochenta con la llamada 'década perdida', etapa en la que se registró el mayor crecimiento de participación económica femenina, explicado en parte por el contexto de crisis económica en las que se vieron envueltas las familias mexicana (Pacheco, 2013) Lo anterior pudiera en parte ayudarnos a comprender, cómo una infancia y juventud vivida en contextos de crisis económica conforma parte de la constitución de un sujeto que prioriza y busca a través de la educación superior tener resuelta la situación básica de supervivencia.

Para estas mujeres el trabajo se constituye en el organizador de sus vidas, son parte del $3 \%$ de mujeres que pueden dedicarse de manera exclusiva al trabajo extra doméstico según lo señala Edith Pacheco (2013). En gran parte el hecho de no contar con una relación de pareja que les demande atención, ni estar obligadas a realizar quehaceres domésticos, así como el no tener hijos ha permitido que sus trayectorias laborales no se vean afectadas negativamente, situación que si ocurre con mujeres casadas y madres de familia (Ariza y de Oliveira, 2006; Zabludowsky, 2014).

4- Ver: Ariza y De Oliveira, 2002, Blanco y Pacheco, 2002, Chant y Craske, 2007, García, 2002, García, Blanco y Pacheco, 1999, Pacheco, 2013, Urrutia, 2002 y Zabludowsky Kuper, 2014. 
El ingreso de la mujer a la esfera laboral, conmociona, diría Lipovetsky (1999) "la relación de las chicas con los estudios, las relaciones entre los sexos, el poder en el seno de la pareja; paralelamente al control de la fecundidad, la actividad femenina expresa la promoción histórica de la mujer que dispone del gobierno de sí misma, así como una nueva posición identitaria femenina" (Lipovetsky, 2012 [1999]: 188)

Lo que tenemos aquí son mujeres profesionistas, que se autodefinen como femeninas, pero con referentes distintos a los tradicionales. Que, si se preocupan por los otros, pero en tiempos y espacios definidos, no las 24 horas. Que ayudan a los demás, pero no negándose a sí mismas, sino empoderándose para ejercer poder y resolver problemas, realizar gestiones. Mujeres que no les preocupa- y puede que además gocen-, de ser definidas como perras, hijas de la chingada, pues esos adjetivos son reinterpretados como prueba de su capacidad y autoridad.

Gilles Lipovetsky expone como el compromiso de las mujeres con la esfera laboral puede leerse en el marco de sociedades posmodernas, por un lado, como una expresión de la preocupación por uno mismo, y por otro lado, "revela la voluntad de ser reconocido como agente individual responsable de su propia vida" (Lipovetsky, 2012 [1999]: 205). Lo anterior habría que destacar, no está exento de contradicciones. Si bien las mujeres entrevistadas viven con intensidad y orgullo sus actividades profesionales, negando sentir arrepentimiento por alguna decisión con relación a su vida personal no-profesional en el marco de su trayectoria laboral -por ejemplo, su no maternidad, o su no vida en pareja-, son conscientes de que "no se puede tener todo en la vida", que la plenitud que viven implica renuncias, y que esas renuncias hasta el momento han valido la pena.

\section{Referencias}

Amorós, Celia. 1994. Feminismo, igualdad y diferencia. México: UNAM-PUEG.

Ariza, Marina y Orlandina De Oliveira.2002. Cambios y continuidades en el trabajo, la familia y la condición de las mujeres. En Estudios sobre las mujeres y las relaciones de género en México: aportes desde diversas disciplinas, coordinado por Elena Urrutia. México: El Colegio de México, 43-86.

Ariza, Marina y Orlandina De Oliveira. 2006. Regímenes sociodemográficos y estructura familiar: los escenarios cambiantes de los hogares mexicanos. Estudios Sociológicos, 24(70): 3-30.

Bauman, Zygmunt. 2010. Identidad. Buenos Aires: Lozada.

Blanco, Mariza y Edith Pacheco. 2002. La mujer y el trabajo en México: algunas aportaciones del PIEM. En Estudios sobre las mujeres y las relaciones de género en México: aportes desde diversas disciplinas, coordinado por Elena Urrutia. México: El Colegio de México, 121-164.

Castañeda Rentería, Liliana. 2007. Ser universitario: los alumnos y alumnas del Centro Universitario de la Costa Sur de la Universidad de Guadalajara. Tesis de Maestría, Guadalajara: UDG.

Castañeda Rentería, Liliana. 2013. Género, profesión y estrategias identitarias de las estudiantes de la carrera de abogado. Tercer Milenio, Periodismo y Comunicaciones, 18(26): 13-22.

Chant, Sylvia y Nikki Craske. 2007. Género en Latinoamérica. México: CIESAS.

Damián, Araceli. 2013. Mujeres y hombres frente al trabajo socialmente necesario. En Mujeres y diversidad laboral en México, coordinado por María Eugenia De la O. Guadalajara, Jalisco, México: Universidad de Guadalajara, 65-100. 
De la O, María Eugenia. 2013. Mujeres y diversidad laboral en México. Mexico: Universidad de Guadalajara.

García Guzmán, Brígida, Blanco Sánchez, Mercedes y Edith Pacheco Gómez Muñóz. 1999. Género y trabajo extradoméstico.En Mujer, género y población en México, coordinado por Brígida García. México: El Colegio de México y la Sociedad Mexicana de Demografía, 273-316.

García, Brígida.2002. Reestructuración económica, trabajo y autonomía femenina en México. En Estudios sobre las mujeres y las relaciones de género en México: aportes desde diversas disciplinas, coordinado por Elena Urrutia. México: El Colegio de México, 87-120.

Lipovetsky, Guille. 2012. La tercera mujer. México: Anagrama.

Luna Santos, Silvia. 2005. Avances en educación superior: irrupción femenina y continuidad masculina. Economía, Sociedad y Territorio, 5(17): 219-246. http://dx.doi.org/10.22136/est002005321

Marrero, Adriana y Natalia Mallada. 2009. La Universidad transformadora. Montevideo: Facultad de Ciencias Sociales, Universidad de la República.

Mingo, Araceli. 2006. ¿Quién mordió la manzana? Sexo, origen social y desempeño en la universidad. México. UNAM/CESU/PUEG/FEC.

Miranda Guerrero, Roberto.2007. Mujeres, educación superior e igualdad de género. Revista de Investigación Educativa, (4): 1-30.

Pacheco, María Edith. (2013). Mujeres y heterogeneidad laboral en los mercados de trabajo hoy. En $\mathrm{Mu}$ jeres y diversidad laboral en México, coordinado por María Eugenia De la O. Guadalajara: Universidad de Guadalajara, 33-64.

Reséndiz Núñez, Daniel.2000. Futuros de la educación superior en México. México: Siglo XXI.

Romo, Rosa.2000. Una mirada a la construcción de identidades. Guadalajara: Universidad de Guadalajara.

Sanhueza, Tatiana.2005. De prácticas y significacias en la maternidad, transformaciones en identidad de género en América Latina. La Ventana, 22: 146-188.

Tolentino, Hedalid.2013. Curso de vida e identidades profesionales femeninas: las ejecutivas en la alta dirección empresarial en la Ciudad de México. En Mujeres y diversidad laboral en México, coordinado por María Eugenia De la O. Guadalajara: Universidad de Guadalajara.

Urrutia, Elena.2002. Estudios sobre las mujeres y las relaciones de género en México: aportes desde diversas disciplinas. México: El Colegio de México.200-230.

Zabludowsky, Gina. 2014. Empresarias y ejecutivas en México: diagnóstivos y desafíos. Mujeres y hombres en la dirección de empresas en México. Ponencia presentada en 40 Congreso Nacional de Ciencias Sociales, San Cristobal de las Casas. 